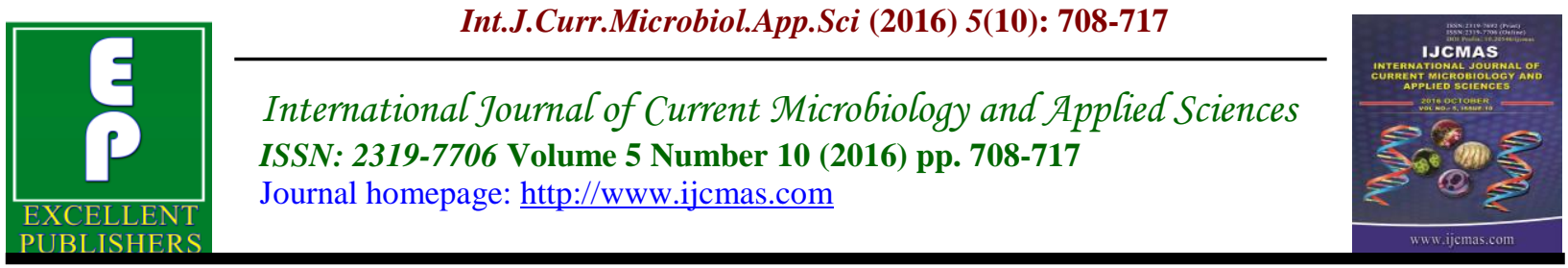

Original Research Article

http://dx.doi.org/10.20546/ijcmas.2016.510.077

\title{
Isolation of Tomato Fruits Mycoflora and Evaluation in vitro and in vivo by Trichoderma harzianum
}

\author{
Mokhtar Hamitou ${ }^{1,2^{*}}$, Laid Dehimat ${ }^{2}$ and M. Mourad Senoussi ${ }^{1}$ \\ ${ }^{1}$ Laboratory of Bimolecular and Plant Amelioration, Larbi-Ben-M'hidi University, Oum El \\ Bouaghi, BP 358, Constantine Road, 04000, Algeria \\ ${ }^{2}$ Laboratory of Mycology, Biotechnology and Microbial activity, University of \\ Mentouri, Constantine, 25000. Algeria \\ *Corresponding author
}

\section{Keywords}

Stemphylium sp.,

soft rot,

Aspergillus niger,

Lycopersicon

esculentum,

confrontation,

slide methods,

inhibition

Article Info

Accepted:

20 September 2016

Available Online:

10 October 2016
A B S T R A C T

The present investigation aimed is to isolate and identify the mycetes accompanying the tomato fruits (Lycopersicon esculentum), and to evaluate in vitro and in vivo the ability of T.harzianum to control the isolated mycetes. Some infected tomato fruits by mycetes were brought from Oum-elbouaghi market. The results of isolation allowed the identification of Stemphylium sp. and Aspergillus niger. One isolate of T.harzianum / Hypocrea lixii was utilized in this study. The results of direct confrontation (in vitro) of T.harzianum against Stemphylium sp. and A.niger on PDA medium indicated the inhibition of mycelium growth in variable degrees; it was equal in the fourth day of the experiment to $54.54 \%$ and $52.17 \%$ for Stemphylium sp. and A.niger respectively. However, it did not show any growth of the tested fungus when re-planting a disk from the interaction hyphal area between T.harzianum and Stemphylium sp. or A.niger from dual cultures, while T.harzianum grew alone in the plates. The microscopic observations of mycelia of dual culture in slide methods showed that the mycelia of T.harzianum induced degradation and aggregated the spores and analyzed the mycelia of A.niger, overgrowing the mycelia of Stemphylium $s p$ and coiled around of them and degrading them. In vivo screening showed after 10 days of incubation an antagonistic activity of T.harzianum against the tested fungus on tomato fruits, with inhibition equal to $100 \%$ and 95\% in Stemphylium sp. and in A.niger respectively, compared with controls. Beside we found that the treated fruits with T.harzianum stayed saints as compared with control, when Stemphylium and A.niger soft rot infected all surface the test fruits. This strain of T.harzianum may offer potential for biological control of tomato Stemphylium and A.niger soft rot.

\section{Introduction}

Tomato plant (L.esculentum L.) originated South America belongs to Solanaceae family is a widely grown vegetable in the world. It is the most popular vegetable world-wide. The leading producer of tomato in the world is USA followed by China, Italy, Turkey, Egypt, Spain, Romania, Brazil and Greece (Wani, 2011). In Algeria, the 
tomato crop is grown over an area of 292000 hectares, it accounts for $51 \%$ of the total vegetable production (Nechadi et al., 2002). Tomato crop suffered every year from a number of pathogenic diseases (Wani, 2011). The fungus Stemphylium solani causes leaf blight of tomato in Brazil (Mehta, 1998 ). Most the Stemphylium species on record as plant pathogens in Japan (Daisuke et al., 2015). A.niger caused a disease called black mold on certain fruits and vegetables such as grapes, tomato, onions and peanuts (Sharma, 2012). Mallek et al., (1995) reported that the A.niger was a one of the most common pathogens and caused loss of $25 \%$ in tomato fruit in Egypt. A.niger was responsible for the post harvest rot of Tomato fruits in Nsukka (Nigeria) and the pathogenesis tests confirmed that, the fungal isolate is one of the causal agents of the rot (Jude and Nneka, 2012). Chemical compounds have been used to control plant diseases, this has no doubt increased crop production but with the attendant deterioration of the environment and human health. In addition to killing target pathogens, pesticides may also kill various beneficial organisms and their toxic effects can persist in the soil but abuse in their employment has favored the development of pathogens resistant (Kamala and Indira, 2012; Nneka and Uken, 2013). The Algerian farmer used the chemical fungicides to control the fungal diseases of tomato plants, but in more time the treatment traces are observed in tomato fruits, because they usually aren't rinsed fruits before marketing (fig.1.1). Biological control using potential microorganisms having strong antifungal activity is coming up as an alternative strategy for disease management, which is also ecologyconscious and environment friendly (Kamala and Indira, 2012). Several biocontrol strategies have been proposed for controlling the plant pathogens, but practical applications are still limited (Hibar et al., 2007). Trichoderma species are common soil-inhabiting fungi that have been developed as effective biocontrol agents against various phytopathogenic microorganisms (Bel Haj Khethr et al., 2008).

The aim of the present investigation was to isolate and to identify the mycetes accompanying the tomato fruits (Lycopersicon esculentum), and to evaluate the in vitro and in vivo ability of T.harzianum to control that isolated mycetes.

\section{Materials and Methods}

\section{Fungal strains}

Stemphylium sp. and Aspergillus niger were isolated from infected tomato fruits, which were brought from Oum-elbouaghi market, and identified based on the microscopic observations of their reproductive and colony characteristics in laboratory of microbiology, university of Oum-elbouaghi (Algeria) (Botton et al., 1990; Rémi, 1997; Robert et al.,, 1981). A local strain of T.harzianum / Hypocrea lixii , was identified in the same laboratory and verified in Walloon Center of Biology Industrial, University of Liege, Belgium.

In vitro Evaluation of the antagonistic capability of T.harzianum against Stemphylium sp. and A. niger, on PDA medium (direct confrontation)

To study the direct confrontation between T.harzianum and Stemphylium sp. or A.niger Two plugs of mycelium ( $8 \mathrm{~mm}$ diameter) were cut from the margins of actively cultures growing on PDA medium, one carrying the stock of T.harzianum and the other of Stemphylium sp. or A.niger. Then they placed at the periphery of Petri plates 
( $9 \mathrm{~cm}$ in diameter) at the same distance on PDA medium (dual cultures). One plug of Stemphylium sp. or A.niger were maintained as controls (alone cultures). Each replicate has three plates. Both the dual and alone cultures were incubated at $25^{\circ} \mathrm{c}$ for four days, and measurement of colony diameters (in millimeters) was taken every 24 hours. The percentage of inhibition growth (I) was calculated by using the formula given below: [I $(\%)=(1-\mathrm{T} / \mathrm{C}) \mathrm{x}$ 100]. Where: $\mathrm{I}=$ Percentage inhibition of pathogen growth by antagonists. $\mathrm{C}=$ Radial growth in control. $\mathrm{T}=$ Radial growth in the treatment (Berber et al., 2009; Hamitou and Dehimat, 2015).

\section{Evaluation of dual culture using slide method}

For each pathogen (Stemphylium or A.niger)-T.harzianum interaction, a clean slide was placed in $9 \mathrm{~cm}$ diameter plates and sterilized. Following that, a small amount of PDA medium was spread over the slide to make a thin PDA film on the slide. The 5 $\mathrm{mm}$ discs of one week old of each pathogen and $T$. harzianum isolates were placed on the opposite sides of the slide $3 \mathrm{~cm}$ apart on the PDA surface.

Then $5 \mathrm{ml}$ of distilled water was added to the plate to prevent drying and then incubated at $25^{\circ} \mathrm{c}$ for a week. At the end of incubation period, region of contact between $T$. harzianum-Pathogen hyphae was stained with lacto phenol and cotton blue and examined under a light microscope (AlSaeedi and Moqdad, 2014).

\section{Preparation of tomato fruits}

Intact red tomatoes (L.esculentum Mill.), uniform in size and color, were obtained from the market of Oum-Elbouaghi city. The fruits were surface-sterilized by soaking in $2 \%$ aqueous sodium hypochlorite for 5 min, they were thoroughly rinsed with sterile distilled water, dried using sterile filter papers, and then wounded by removing a rectangular area at the equator of each fruit, $(3 \mathrm{~cm} \times 4 \mathrm{~cm})$ in diam. and $3 \mathrm{~mm}$ in depth, from the surface, using a sterile scalpel (Berrada et al., 2012).

In vivo. Evaluation of the antagonistic capability of T.harzianum against Stemphylium sp. and A.niger on tomato fruits

Fresh cultures of Stemphylium sp., A.niger and T.harzianum were used for each experiment to evaluate the antagonistic activity. Two plugs of mycelium $(8 \mathrm{~mm}$ diameter) were cut from the margins of actively cultures growing on PDA medium, one carrying the stock of T.harzianum and the other of Stemphylium sp. or A.niger were then placed one beside of the other at the center of the rectangular area of tomato fruits.

As control, fruits were either inoculated with Stemphylium sp. or A.niger alone. The fruits were then stored at $20^{\circ} \mathrm{C} \pm 2$.for 10 days in autoclaved glass jars with hermetic covers. The percentage of disease reduction of Stemphylium or A.niger rot on tomato fruits, was calculated using the following formula:

$(\%)=(\mathrm{A}-\mathrm{B}) / \mathrm{A} \times 100$

where $\mathrm{A}$ is the lesion diameter recorded in tomato fruit inoculated with the Stemphylium sp. or A.niger alone

$\mathrm{B}$ is the lesion diameter recorded in infected tomato fruits treated with T.harzianum. All in vivo antagonism assays were made in triplicate (Berrada et al., 2012; Hamitou and Dehimat, 2015). 


\section{Results and Discussion}

In vitro Evaluation of the antagonistic capability of T.harzianum against Stemphylium sp. and A.niger on PDA medium (direct confrontation)

The results of the direct confrontation between T.harzianum against Stemphylium sp. and A.niger on PDA medium, showed that when the mycelium of the both cultures came due to the contact together, the hyphal growth of Stemphylium sp. and A.niger were found to be inhibited by hyphae of T.harzianum fig.(2.1 and.2.4).That inhibition in the third day of the experiment was: $41.18 \%$ and $29.41 \%$ and in the fourth day the amounts were: $54.54 \%$ and $52.17 \%$ for Stemphylium $s p$ and A.niger respectively (table1) and (fig.3). Besides, showed no growth of mycelia of Stemphylium sp. or A.niger when re-planting the disks from the interaction hyphal area between T.harzianum and Stemphylium sp. or A.niger from dual cultures, while T.harzianum grew alone in the plates Fig (2.3 and 2.6).

\section{Evaluation of dual culture using slide methods}

The microscopic observations of mycelia of dual culture in slide methods showed that the mycelia of T.harzianum overgrowing the mycelia of Stemphylium $s p$ and coiled around of them and degrading them fig.( 4.2, $4.3)$; induced degradation and aggregated the spores and analyzed the mycelia of A.niger fig $(4.5,4.6)$, compared with controls fig(4.1 and 4.4).

In vivo Evaluation of the antagonistic capability of T.harzianum against Stemphylium sp. and A.niger on tomato fruits

After 10 days of incubation the T.harzianum showed an inhibition activity with a different ratios against Stemphylium sp. and A.niger on tomato fruits. The latter was equal to: $75 \%$ and $91.66 \%$ in the seventh day and the amount in the tenth day reached $100 \%$ and $95 \%$ for Stemphylium $s p$ and A.niger respectively (fig.5).

Beside we found that the treated fruits with T.harzianum stayed saints (fig. 6.d) and (fig.7.d) compared with controls when Stemphylium and A.niger soft rot infected all surface the fruits (fig.6.c) and (fig.7.c).

Table.1 In vitro. Effect of T.harzianum on the mycelia growth of

Stemphylium sp. and A.niger, on PDA medium.

\begin{tabular}{|c|c|c|c|c|c|}
\hline & \multirow[b]{2}{*}{ Fungus species } & \multicolumn{4}{|c|}{ Radial growth rate (mm) after: } \\
\hline & & 24 hour & 48 hour & 72 hour & 96 hour \\
\hline \multirow[b]{2}{*}{ Dual culture } & T.harzianum & 30 & 78 & 130 & 130 \\
\hline & Stemphylium sp & 6 & 16 & 20 & 20 \\
\hline Alone culture & Stemphylium sp & 10 & 20 & 34 & 44 \\
\hline $\begin{array}{l}\% \text { inhibition of } \\
\text { mycelia growth }\end{array}$ & Stemphylium sp & 40 & 20 & 41.18 & 54.54 \\
\hline \multirow[b]{2}{*}{ Dual culture } & T.harzianum & 34 & 80 & 130 & 130 \\
\hline & A.niger & 10 & 20 & 24 & 22 \\
\hline Alone culture & A.niger & 12 & 22 & 34 & 46 \\
\hline $\begin{array}{l}\% \text { inhibition of } \\
\text { mycelia growth }\end{array}$ & A.niger & 16.16 & 9.1 & 29.41 & 52.17 \\
\hline
\end{tabular}




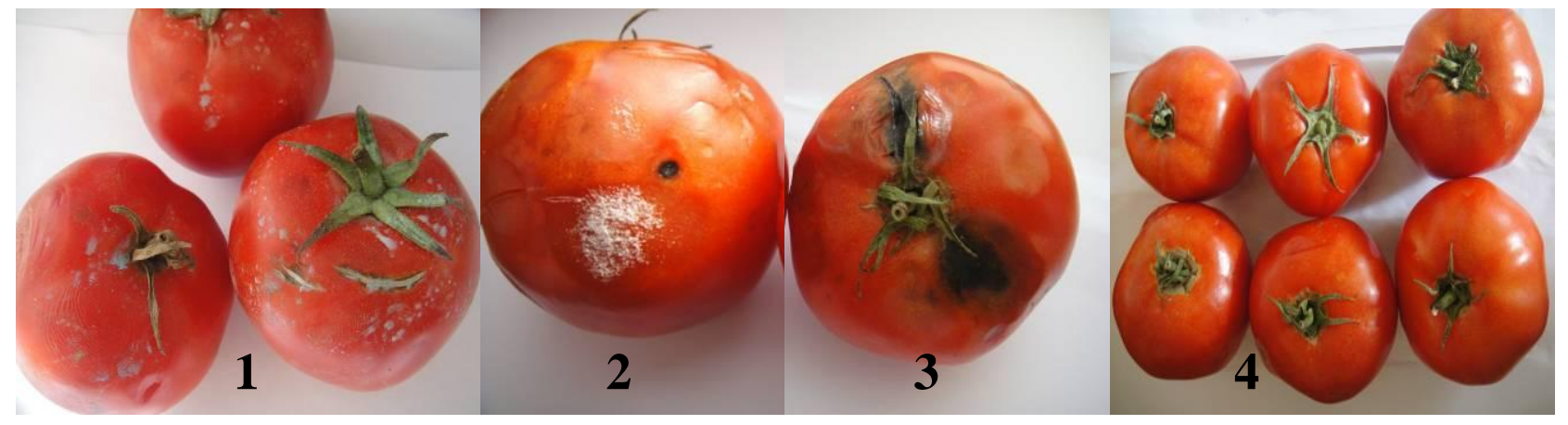

Fig.1 Treated tomato fruits with fungicide, 1. Infected tomato fruits with A.niger rot,2., Infected tomato fruits with Stemphylium rot,3., Some tomato fruits utilized in the in vivo test, 4.

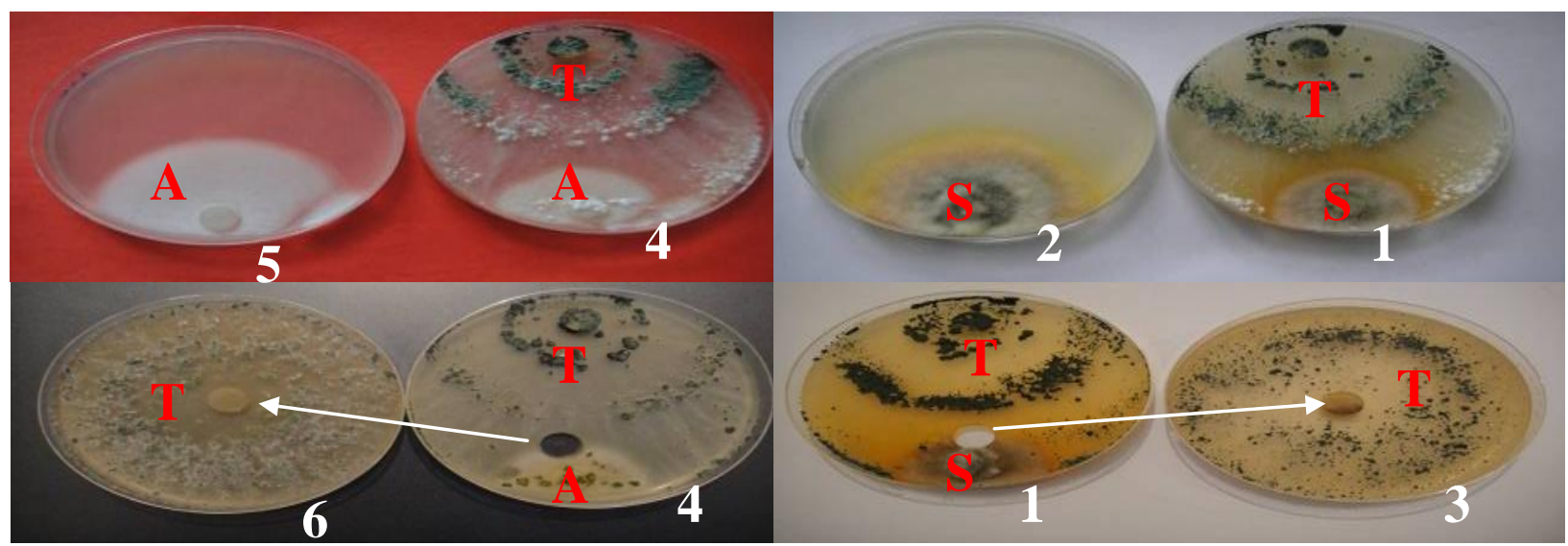

Fig.2 In vitro effect of T.harzianum against Stemphylium sp. and A.niger. dual cultures(1)and (4)., controls (2) and (5)., re-planting plates (3) and (6). $\mathrm{S}=$ Stemphylium , A= Aspergillus, $\mathrm{T}=$ Trichoderma. 

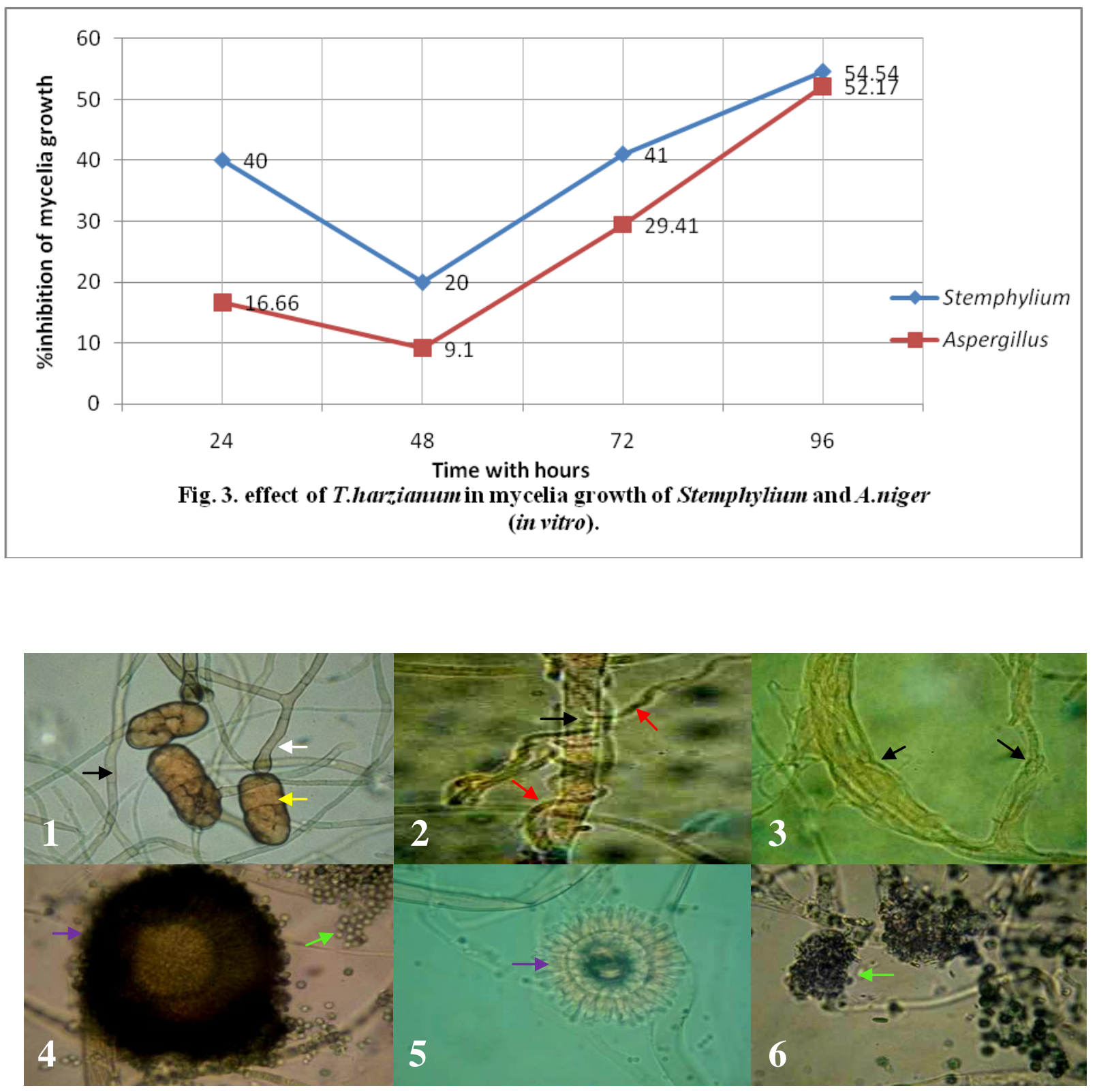

Fig.4 Microscopic observations of the in vitro effect of T.harzianm against Stemphylium sp. and A.niger. Decomposition phenomenon(3), (5) and(6); Mycoparasitism phenomenon (Trichoderma hyphal coiling around of Stemphylium hyphal),2. Controls,1 and 4. Stemphylium ( hyphe=black arrow, sporophore $=$ white arrow, dictyospore $=$ yellow arrow $)$, A.niger ( conidia= green arrow, vesicle=purple arrow., Trichoderma hyphe $=$ red arrow. 

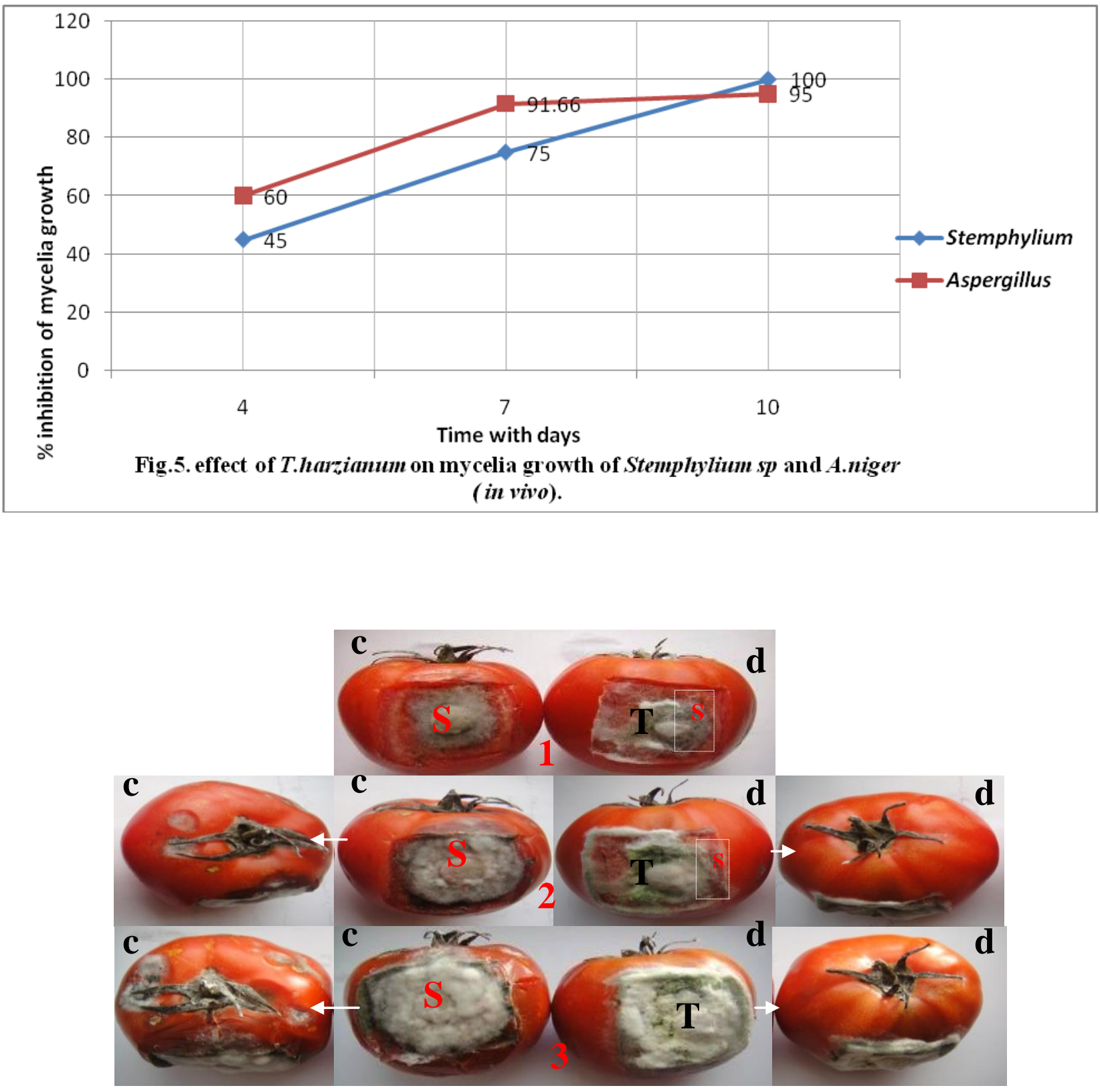

Fig. 6 In vivo effect of T.harzianum against Stemphylium sp. Test( after 4 days, 1. ; after 7 days,2.; after ten days,3.); $\mathrm{c}=$ control., $\mathrm{d}=$ dual culture ; $\quad$ S=Stemphylium, $\mathrm{T}=$ Trichoderma. 


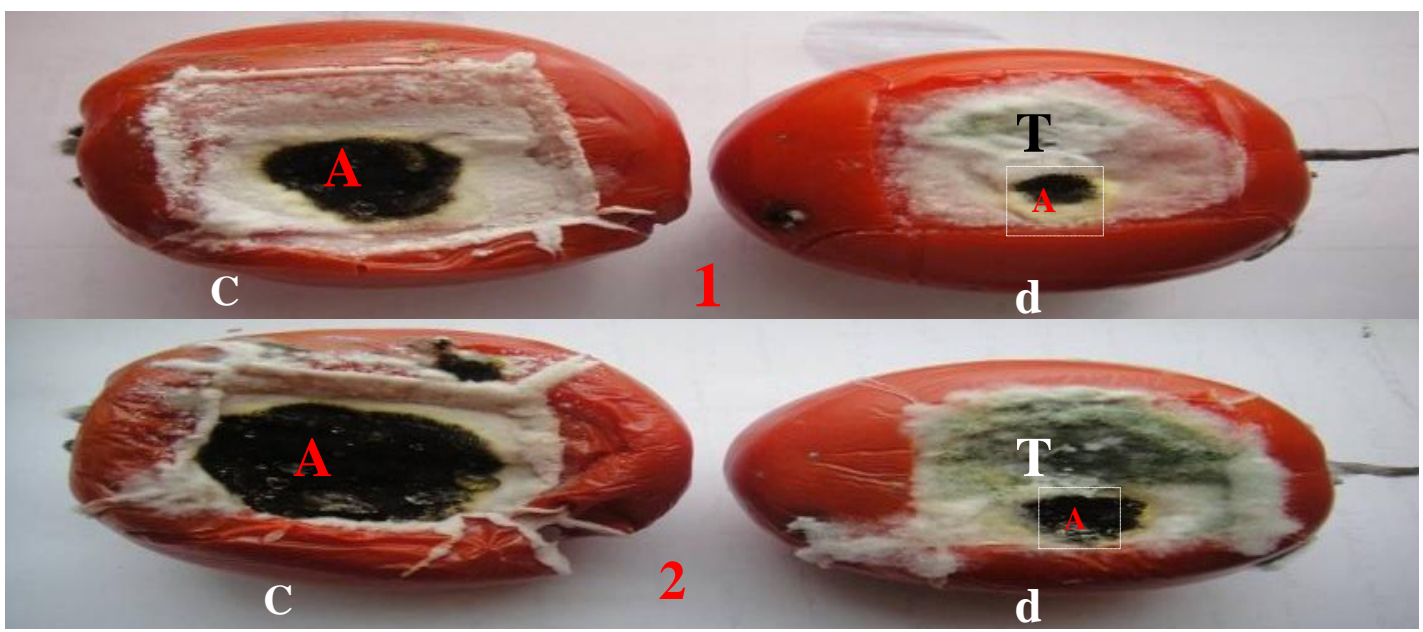

Fig.7 In vivo effect of T.harzianum against A.niger. test( after 4 days, 1.; after 7 days,2.); $\mathrm{c}=$ control., $\mathrm{d}=$ dual culure. $\mathrm{A}=$ A.niger, $\mathrm{T}=$ Trichoderma .

In this investigation, this local strain of $T$. harzianum showed a high efficiency both in vitro and in vivo against Stemphylium sp. and A.niger. This results was confirmed by many paper studies, where found that the T.harzianum could restrict growth of A.niger in vitro (dual culture) with $75 \%$ and amounted to reach $78.77 \%$ (Agrwal et al., 2011; Lone et al., 2012). The T.harzianum can inhibited the growth of Bipolaris sp., F.oxysporium, Fusarium sp. and R.solani with a different ratios, and inhibited there spore's formation, with recording a different degrees of parasitism (Azza and Allam, 2004; Berber et al., 2009; Comporota, 1985; Hibar et al., 2005). T.harzianum strains produced an inhibitor metabolites as 1, 3- bglucanase and chitinase which were inhibited the growth of G.graminis var. tritici, F.culmorum and F.moniliforme on PDA medium (Cigdem and Merih, 2004). T.harzianum can produced nonanoic acid into a liquid culture medium. The latter has a strongly affected both mycelial growth and spore germination of the cacao pathogen (Crinipellis perniciosa and Moniliophthora roreri) (Anejaa et al., 2005). T.harzianum reduced disease incidence significantly against P.ultimum and R.solani on both cucumber and tomato on greenhouse (Johanne et al., 2002). In the similar study, Yacoub, (1999), found that the Trichoderma $s p$ reduced the lesion development and number of conidiophores of Botrytis sp. in foliar discs of strawberry test, compared with the non-treated (control). This local strain of T.harzianum may offer potential for biological control of tomato Stemphylium and A.niger soft rot.

\section{References}

Agarwal, T., A. Malhotra., M. Biyani., and Trivedi, P.C. 2011. In vitro interaction of Trichoderma isolates against Aspergillus niger, Chaetomium sp. and Penicilium sp. Indian J. Fundamental and Appl. Life Sci., 1: 125- 128.

AL-Saeedi, S.S., and Moqdad AL-Ani, B. 2014. Study of antagonistic capability of Trichoderma harzianum isolates against some pathogenic soil borne 
fungi. Agric. Biol. J.N. Am., 5: 15-23.

Anejaa, M., J.T. Gianfagnaa., and Prakash K.H. 2005. Trichoderma harzianum produces nonanoic acid, an inhibitor of spore germination and mycelial growth of two cacao pathogens. Physiol. Mol. Plant Pathol., 67: 304307.

Azza, A.T., and Allam, D.A. 2004. Improving cumin production under soil infestation with Fusarium Pathogen 1- screening of biocontrol agents. Ass. Univ. Bull. Environ. Res., 2: 35- 45.

Bel Haj Khethr, F., S. Ammar., D. Saïdana., M. Daami., J. Chriaa., K. Liouane., M. A. Mahjoub., A. N. Helal., and Mighri, Z. 2008. Chemical composition, antibacterial and antifungal activities of Trichoderma sp. growing in Tunisia. Annals of Microbiol., 58: 303- 308.

Berber, F., A.O. Touhami., A. Badoc,. et Douira, A. 2009. Antagonisme in vitro et in vivo de deux Trichoderma à l'egard de quatre éspèces de Bipolaris pathogens sur le sorgho. Bull, Soc. Pharm., Bordeaux. 148:93-114.

Berrada, I., Benkhemmar, O., Swings, J., Bendaou, N. and Amar, M. 2012. Selection of halophilic bacteria for biological control of tomato gray mould caused by Botrytis cinerea. Phytopathologia Mediterranea, 51: 625-630.

Botton, B., A. Breton., M. Fevre., S. Gauthir., J. P. Larpent., P. H. Gay., P. Reymond., J. J. Sanglier., Y. Vayssier and Veau, P. 1990. Moisissures utiles et nuisible importance industrielle. . Masson., Paris, Milan, Barcelone, Mexico.

Camporota, P. 1985. Antagonisme in vitro de Trichoderma spp. vis-à-vis de Rhizoctonia solani Kuhn. Agronomie. 5:111- 115 .
Cigdem, K., and Merih, K 2004. In vitro antifungal activity of strains of Trichoderma harzianum. Türk. J. Biol., 28: 111-115.

Daisuke, K., M. Tomoo., I. Kazunori., K.Gan., H. Hong, Long., F. Naruto., T. Kenichi., and Seiya, T. 2015. Taxonomic re-examination of several Japanese Stemphylium strains based on morphological and molecular phylogenetic analyses. J. Gen. Plant Pathol., 81: 358- 367.

Hamitou, M., and Dehimat, L. 2015. In vitro and in vivo efficiency of Trichoderma harzianum againsT Phoma and Glocladium soft rot occurred on tomato fruits (Lycopersicon esculentum). Int. J. Curr. Microbiol. App. Sci., 4: 141-147.

Hibar, K., D.R. Mejda., K. Haifa., and Mohamed, E. 2005. Effet inhibiteur in vitro et in vivo du Trichoderma harzianum sur Fusarium oxysporium f. sp. Radicis lycopersici. Biotechnol. Agron. Soc. Environ., 9: 163- 171.

Hibar, K., M. Daami-Remadi., and El Mahjoub, M. 2007. Induction of resistance in tomato plants against Fusarium oxysporum f. sp. radicislycopersici by Trichoderma spp. Tunisian J. Plant Protection, 2: 4758.

Johanne, C., L. Lucie., O. Pierre. et Richard, R. B. 2002. Utilisation d'une souche indigène de Trichoderma harzianum contre cinq agents pathogènes chez le concombre et la tomate de serre au Québec. Phytoprotection, 83:73- 87.

Jude, A.U., and Nneka, V.C. 2012. Preliminary Investigations of the Cause of Post-harvest Fungal Rot of Tomato. J. Pharm. Biol. Sci., 4: 3639.

Kamala, T., and Indira D.S. 2012. Biocontrol properties of indigenous Trichoderma isolates from North-east 
India against Fusarium oxysporum and Rhizoctonia solani. African $J$. Biotechnol., 11: 8491- 8499.

Lone, A.M., M.R. Wani., S.A. Sheikh., S. Sahay., and M. Suliman Dar, M.S. 2012. Antagonistic Potentiality of Trichoderma harzianum Against Cladosporium spherospermum, Aspergillus niger and Fusarium oxysporum. J. Biol. Agri. Healthcare, 2: $72-76$

Mallek, A.Y., S.K. Hemida., and Bagy, M.K. 1995. Studies associated with tomato fruit and effectiveness of some commercial fungicides against three pathogen. Mycopathologica, 130: 109116.

Nechadi, S., F. Benddine., A. Moumen., and M. Kheddam. 2002. Etat des maladies virales de la tomate et stratégie de lutte en Algérie. EPPO Bull., 32: 21-24.

Nneka, C.V., and Ukeh, J.A. 2013. Efficacy of Aframomum melegueta and
Zingiber officinale extracts on fungal pathogens of tomato fruit. J. Pharm. Biol. Sci., 4: 13- 16.

Rémi, C. 1997. Identifier les champignons transmis par les semences. INRA, France.

Robert, A.S., S.H. Ellen and Connie, A.N.V. 1981. Introduction to -Food-borne Fungi C.B.S. Institute of the Royal Netherlands, Academy Arts and Sciense.

Sharma, R. 2012. Pathogenecity of Aspergillus niger in plants. Cibtech J. Microbiol., 1: 47- 51.

Wani, A.H. 2011. An overview of the fungal rot of tomato. Mycopath., 9: 33- 38.

Yacoub, B. 1999. Biological effect of two strains of microorganisms antagonistic to Botrytis Cinerea causal organism of gray mold on strawberry. An- najah Univ. J. Res., 13: 67- 83.

\section{How to cite this article:}

Mokhtar Hamitou, Laid Dehimat and M. Mourad Senoussi. 2016. Isolation of Tomato Fruits Mycoflora and Evaluation in vitro and in vivo by Trichoderma harzianum. Int.J.Curr.Microbiol.App.Sci. 5(10): 708-717. doi: http://dx.doi.org/10.20546/ijcmas.2016.510.077 